\title{
Determination, Reproducibility and Illustration of the Helical Axes of the knee after Total Arthroplasty
}

\author{
Florian Forelli1 ${ }^{1,2}$, Jean Mazeas ${ }^{1}$, Amaury Vandebrouck ${ }^{3}$, Pascal Duffiet ${ }^{3}$, Louis Ratte ${ }^{3}$ and Maude Traulle Ma $^{1,2}$ \\ ${ }^{1}$ Researcher Physical Therapist in OrthoLab, Clinic of Domont, France \\ ${ }^{2}$ Co-Director in OrthoLab, OrthoLab, Clinic of Domont, France \\ ${ }^{3}$ Orthopaedic Surgeon, Clinic of Domont, France
}

Submission: April 07, 2020; Published: April 17, 2020

*Corresponding author: Florian Forelli, OrthoLab, Clinic of Domont, 85 route de Domont 95330 Domont, France

Abstract

The biomechanical models are evolving in order to be as close as possible to the clinic. Quantified movement analysis offers predictive and / or functional methods that help determine and model functional axes known as helical axes that seem today to represent the means closest to human joint movement. The knee is a joint with complex movements subject to kinematic modifications. The knee joint changes that occur during life seem to modify the helical axes and disrupt the kinematics of the joint. These alterations cause joint replacements by total knee arthroplasty which have the particularity of being based on the knee axes in order to restore the anterior kinematics of the knee with the aim of early functional recovery. The current design of total knee prostheses makes it possible to partially restore the functional axes of the knee, which could in the long-term cause biomechanical disturbances responsible for sometimes unsatisfactory results.

Keywords: Biomechanical models; Helical Axis; Total Knee Arthroplasty; Kinematics modifications

\section{Introduction}

The study of knee biomechanics describes the function of the knee joint in terms of mechanical components [1]. The field of biomechanics includes both the study of movements (kinematics) by quantifying the movements of the segments of the human body and the study of forces and torques (kinetics) acting on the segments and joints. The authors describe the flexion / extension movement as the main movement of the knee, which has 6 degrees of freedom. Thus, it can perform 3 rotations (flexion / extension, abduction / adduction, medial rotation / lateral rotation) and 3 displacements (anteroposterior, mediolateral and proximodistal) [2]. In the context of certain biomechanical studies, the kinematics of the knee is described in three-dimensional space using an instantaneous axis called the helical axis or "screw axis". The helical movement is determined by the combination of a rotation around a three-dimensional axis with a translation along this same axis [3]. This method describing joint movements, however, is not well understood by the clinical community [4]. And yet, it gives a more realistic representation of the movement of the knee since the joint never performs a single rotation.

\section{Determination of Axes and Methods}

The quantified motion analysis is based on the principles of mechanics applied to the living. Indeed, for the study of movement, the human being is considered as a rigid poly-articulated mechanical object (assumed to be undeformable) which can be broken down into several segments (bone segments). In three dimensions, a segment is associated with a reference frame defined by three non-collinear points (triangle). Unlike a straight line, the triangle has an orientation and a position. The principle of modeling is therefore to associate three points and thus to determine the frame of reference specifically linked to each anatomical segment of the body. It is from these reference frames that we can calculate the movements of translations and rotations of the segments. By linking the movements of the adjacent 


\section{Orthopedics and Rheumatology Open Access Journal (OROAJ)}

segments, the joint angles are obtained. This modeling principle uses a so-called predictive approach.

The Vicon ${ }^{\circledR}$ Plug-in-Gait model, used in most gait analysis laboratories, applies a method in the calculation of the center of rotation of the knee [5]. To determine this, the PIG estimates the hip CoR using three markers located on the pelvis. It then defines the derived hip CoR and with other markers on the thigh, estimates the knee CoR. The PIG finally uses the joint center of the derived knee and two other markers on the upper ankle to estimate the CoR of the ankle [6]. Therefore, errors in the proximal joints are passed on to the distal joints. This observation is all the more marked in subjects where bone markers are difficult to identify around the pelvis, for example obese or overweight subjects. According to Neptune and Hull as early as 1995 [7], shows that the results of these approaches, which use regression equations, for the hip joints have been found to be inaccurate by about $2 \mathrm{~cm}$ compared to X-ray measurements.

Leardini et al. (1999) have shown that CoR can be determined more precisely by so-called "functional" methods [8] which use joint movement to determine CoR and axis of rotation. These are therefore determined independently of each other. The techniques used in this approach are distinguished in 2 categories as explained by Ehrig et al. [9] in 2006:

i. Spherical adjustment methods: where the joint is assimilated to a sphere according to its degrees of freedom in order to define CoR estimated by the trajectory of the markers $[10,11]$; these methods are based on the assumption that the CoR center is stationary in the global coordinate system

ii. Transformation techniques: where two local landmarks of the adjacent segments are associated along the recorded sequence to find a common landmark in which the estimated articular center is installed; we can then cite Symetrical Center of Rotation Estimation technique or Symmetrical Axis of Rotation Approach.

Several studies have shown the superiority in terms of precision and reliability of functional methods compared to predictive methods including that of Fiorentino et al. [12] even if the authors highlight the fact that all these methods are subject to error due to sensor placement and skin movements. However, it is necessary to add to the transformation techniques an algorithm making it possible to reduce the noise secondary to skin movements such as for example the Optimal Common Shape Technique introduced by Taylor et al. [13].

The functional methods to which the authors refer involve capturing the movement of the subject's lower limb as he explores most of the range of motion possible at all degrees of freedom. Several models of movements have been proposed and according to a study carried out by Camomilla et al. [14], it would seem that the "STAR ARC" movement (star movement then circumduction) shows the best precision and the best reproducibility to determine the CoR hip. To our knowledge, there are only a few studies that aim to determine the optimal calibration movement for the knee.

\section{Determination des axes and TKA}

The long-term satisfaction of patients with TKA is lower than that of total hip replacement, with approximately $20 \%$ of patients dissatisfied [15]. One possible reason is the failure of the artificial joint to recreate the natural kinematics of the knee. Indeed, the arthritic aspect of the knee disrupts the kinematics of the joint. However, it is in relation to these axes that the prosthetic implant will be designed and then implanted. The controlled study of an arthritis population of Meireles et al. [16] reports angular modifications at the level of the axes in the different planes in a flexion-extension movement. Thus, the angles of abductionadduction in the frontal plane are found to be significantly increased $\left(16^{\circ}-8^{\circ}\right)$ while the measurements in the sagittal plane seem to be substantially the same. In addition, the significant determination of the axis movements seems to depend on the method used.

David et al. [17] studies the movements of the axes before and after TKA. This results in a significant difference in the helical and transepicondylar axes (figure 1) in different displacements during flexion-extension according to the initial morphotype (valgus). The great variability between the pre-implant and post-implant helical axes is suggested by the preoperative disturbance of the soft tissue envelope to obtain a neutral mechanical alignment, the sacrifice of anterior cruciate ligament and posterior cruciate ligament, and the modified morphology of the components compared to the natural anatomy of the knee. However, in order to compensate for this modification of the axis, the structure of the TKA induces a regular displacement of the CoR downwards, which implies a rolling type movement, increasing as the knee moves more in flexion. . This movement then compensates for the modification of the axes induced by the TKA (Figure 2).

Furthermore, the study by Colle et al. [18] shows that the TKA modifies the helical axis only in the frontal plane and not in the axial plane (Figure 3). The results of this study are corroborated by the study by Iacono et al. [19], Bruni et al. [20] and a second study by Colle et al. [21]. Only, the correction in the axial plane seems to be decisive [19-22] but seems related to the preoperative valgus [20] and the absence of muscle contraction during anesthesia [23] in order to calibrate the prosthesis on the articular rotary kinematics.

\section{Conclusion}

If the functional methods remain the most "reliable" to reproduce the helical axes of the knee, this approach seems limited in the restoration of its axes after TKA. The absence of voluntary movement linked to the surgery seems disturbed by the restoration of the functional axis in the axial plane, a key determinant of the functional success of a TKA. Thus, the variability of the restoration and the reproducibility of the functional axes of the knee seems to be responsible for the $20 \%$ of knee prostheses dissatisfied over 


\section{Orthopedics and Rheumatology Open Access Journal (OROAJ)}

time. Two hypotheses then emerge: rethink the design of the PTG or improve the method of reproducibility of the helical axes of the knee. Even if the biomechanical approach of the helical axes seems closer to the clinic, it remains difficult to understand in its determination, modeling and reproducibility
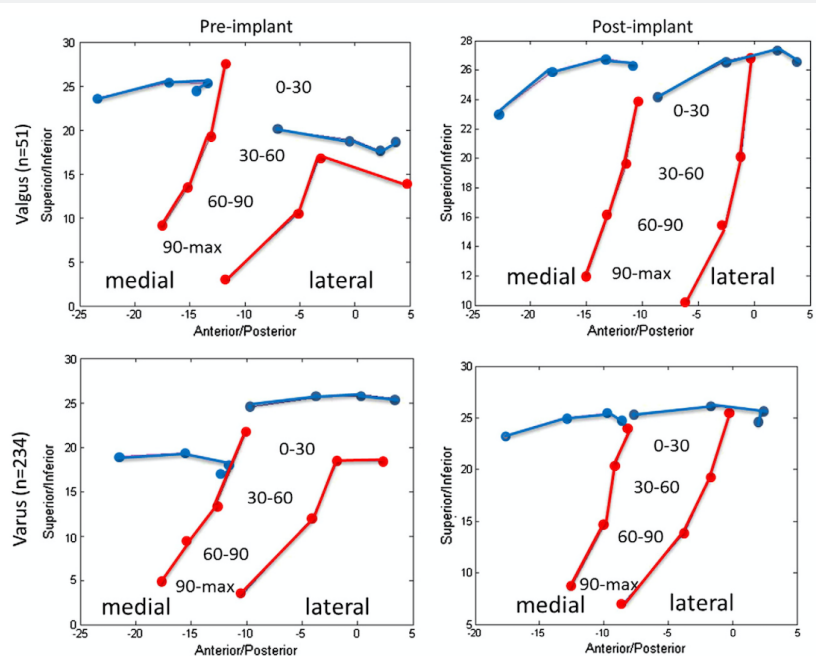

Epicondylar Axis

Figure 1: Comparison of the transepicondylar and helical axes during pre-implant and post-implant flexion for varus and valgus cases [17].

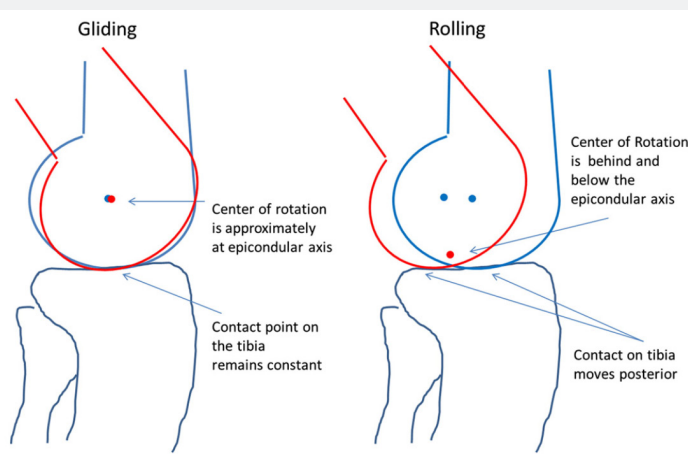

Figure 2: Sliding and rolling movements. The sliding example is similar to the average movement of the lateral condyle post-implant and the rolling example is similar to the pre-implant of the lateral condyle movement.

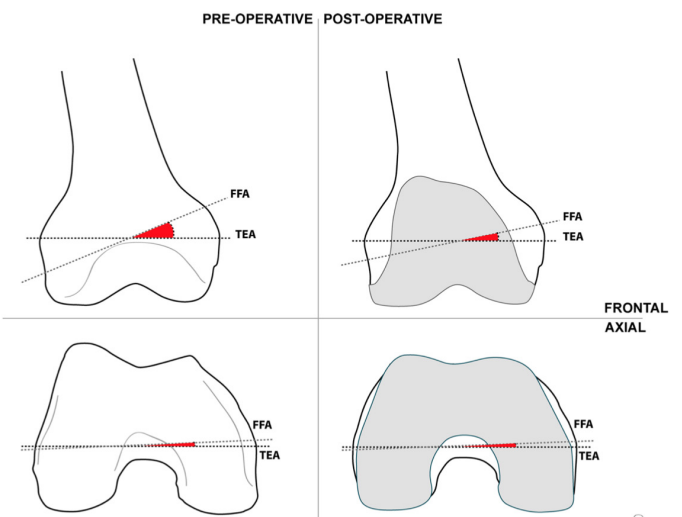

Figure 3: Schematic representation of the preoperative and postoperative helical and transepicondylar angle in the frontal and axial plane. 


\section{References}

1. McLeod W, S Hunter (1980) Biomechanical Analysis of the Knee. Primary Functions as Elucidated by Anatomy Physical Therapy 60(12): 1561-1564.

2. Bull AM, Amis AA (1998) Amis, Knee joint motion:description and measurement. Proc Inst Mech Eng H 212(5): 357-372.

3. Klein P, P Sommerfeld (2008) Biomécanique des membres inférieurs : bases et concepts, bassin, membres inférieurs. 2008, Issy-lesMoulineaux: Elsevier Masson. xxv, 437.

4. Grood ES, Suntay WJ (1983) A joint coordinate system for the clinical description of three-dimensional motions: application to the knee. J Biomech Eng 105(2): 136-144.

5. Vicon® 612 Motion System (2002) Plug in gait modelling instruction. Oxford Metrics LtD.

6. Nair SP, Gibbs S, Arnold G, Abboud R, Wang W (2010) A method to calculate the centre of the ankle joint: A comparison with the Vicon $\AA$ Plug-in-Gait model. Clin Biomech juill 25(6): 582-587.

7. Neptune RR, Hull ML (1996) Methods for Determining Hip Movement in Seated Cycling and Their Effect on Kinematics and Kinetics. J Appl Biomech 12(4): 493-507.

8. Leardini A, Cappozzo A, Catani F, Toksvig-Larsen S, Petitto A, et al. (1999) Validation of a functional method for the estimation of hip joint centre location. J Biomech janv 32(1): 99-103.

9. Ehrig RM, Taylor WR, Duda GN, Heller MO (2006) A survey of formal methods for determining the centre of rotation of ball joints. J Biomech janv 39(15): 2798-2809.

10. Gamage SSHU, Lasenby J (2002) New least squares solutions for estimating the average centre of rotation and the axis of rotation. J Biomech janv 35(1): 87-93.

11. Halvorsen K (2003) Bias compensated least squares estimate of the center of rotation. J Biomech. juill 36(7): 999-1008.

12. Fiorentino NM, Kutschke MJ, Atkins PR, Foreman KB, Kapron AL, et al. (2016) Accuracy of Functional and Predictive Methods to Calculate the Hip Joint Center in Young Non-pathologic Asymptomatic Adults with Dual Fluoroscopy as a Reference Standard. Ann Biomed Eng. juill 44(7): 2168-2180.

13. Taylor WR, Kornaropoulos EI, Duda GN, Kratzenstein S, Ehrig RM, et al. (2010) Repeatability and reproducibility of OSSCA, a functional approach for assessing the kinematics of the lower limb. Gait Posture 32(2): 231-236.

14. Camomilla V, Cereatti A, Vannozzi G, Cappozzo A (2006) An optimized protocol for hip joint centre determination using the functional method. J Biomech 39(6): 1096-1106.

15. Bourne RB, Chesworth BM, Davis AM, Mahomed NN, Charron KD (2010) Patient satisfaction after total knee arthroplasty: who is satisfied and who is not? Clin Orthop Relat Res 468(1): 57-63.

16. S Meireles, F De Groote, S Van Rossom, S Verschueren, I Jonkers (2017) Differences in knee adduction moment between healthy subjects and patients with osteoarthritis depend on the knee axis definition. Gait \& Posture 53(2017) : 104-109.

17. Wilson DA, Astephen Wilson JL, Richardson G, Dunbar MJ (2014) Changes in the Functional Flexion Axis of the Knee Before and After Total Knee Arthroplasty Using a Navigation System. J Arthroplasty $29(7)$ : 1388-1393.

18. Colle F, Lopomo N, Bruni D, Visani A, Iacono F, et al. (2014) Analysis of knee functional flexion axis in navigated TKA: identification and repeatability before and after implant positioning Knee Surg Sports Traumatol Arthrosc 22(3): 694-702.

19. Bruni D, Bragonzoni L, Bontempi M, Iacono F, Neri MP (2015) Does total knee arthroplasty modify flexion axis of the knee? Knee Surg Sports Traumatol Arthrosc 29(4 Suppl): 121-129.

20. D Bruni, F Iacono, F Colle, S Bignozzi, M Marcacci (2015) Does Total Knee Replacement Modify Flexion Axis of the Knee on Frontal and Axial Plane Regardless From Limb Alignment? Knee Surg Sports Traumatol Arthrosc 29(4 Suppl): 121-129.

21. F Colle, D Bruni, F Iacono, A Visani, S Zaffagnini, et al. (2016) Changes in the orientation of knee functional flexion axis during passive flexion and extension movements in navigated total knee arthroplasty, Knee Surg Sports Traumatol Arthrosc 24(8): 2461-2469.

22. Lawrie CM, Noble PC, Ismaily SK, Stal D, Incavo SJ (2011) The FlexionExtension Axis of the Knee and its Relationship to the Rotational Orientation of the Tibial Plateau. J Arthroplasty 26(6 Suppl): 53-58e1.

23. Oussedik S, Scholes C, Ferguson D, Roe J, Parker D (2012) Is Femoral Component Rotation in a TKA Reliably Guided by the Functional Flexion Axis? Clin Orthop Relat Res 470(11): 3227-3232.

\section{Your next submission with Juniper Publishers will reach you the below assets}

- Quality Editorial service

- Swift Peer Review

- Reprints availability

- E-prints Service

- Manuscript Podcast for convenient understanding

- Global attainment for your research

- Manuscript accessibility in different formats

( Pdf, E-pub, Full Text, Audio)

- Unceasing customer service

Track the below URL for one-step submission https://juniperpublishers.com/online-submission.php 